\title{
The Effect Analysis of Different Experimental Methods for the Diagnosis of Invasive Pulmonary Aspergillosis in a Rat Model $^{*}$
}

\author{
Jiancong Lin, Wenming Xu, Ming Li, Yanli Xin, Yuanyuan Niu, Changran Zhang", Zelong Guo \\ Department of Internal Medicine, Huang Pu Hospital of the First Affiliated Hospital, Sun Yat-sen University, Guangzhou, China. \\ Email: ${ }^{\#}$ zhcr2303@sina.com.cn \\ Received August $28^{\text {th }}, 2013$; revised September $25^{\text {th }}, 2013$; accepted October $10^{\text {th }}, 2013$ \\ Copyright (C) 2013 Jiancong Lin et al. This is an open access article distributed under the Creative Commons Attribution License, \\ which permits unrestricted use, distribution, and reproduction in any medium, provided the original work is properly cited.
}

\begin{abstract}
Background: Consensus on the most reliable assays to detect invasive aspergillosis from minimally or noninvasive samples has not been reached. In this study, we compared the efficacy of an enzyme-linked immunosorbent assay (ELISA) for galactomannan (GM) detection and quantitative real-time PCR assay (qRT-PCR) for the diagnosis of invasive pulmonary aspergillosis in a rat model. Methods: Neutropenic, male Sprague-Dawley rats (specific pathogen free; 8 weeks old; weight, $200 \pm 20 \mathrm{~g}$ ) were immunosuppressed with cyclophosphamide and infected with Aspergillus fumigatus intratracheally. Tissue and whole blood samples were harvested on days 1, 3, 5, and 7 post-infection and examined with GM ELISA and qRT-PCR. Results: On day 7, A. fumigatus DNA was amplified from 14 of 48 whole blood samples from immunosuppressed infected rats: day $1(0 / 12)$, day $3(0 / 12)$, day $5(6 / 12)$, day $7(8 / 12)$ post infection. The sensitivity and specificity of the qRT-PCR assay were $29.2 \%$ and $100 \%$, respectively. Receiver operating characteristic curve (ROC) analysis indicated a Ct cut-off value of 15.35, and the area under the curve (AUC) was 0.627. The GM assay detected antigen in sera obtained on day $1(5 / 12)$, day $3(9 / 12)$, day $5(12 / 12)$, and day $7(12 / 12)$ post-infection, and thus had a sensitivity of $79.2 \%$ and a specificity of $100 \%$. The ROC of the GM assay indicated that the optimal cut-off value was 1.40 (specificity, 100\%; AUC, 0.919). Conclusions: The GM assay was more sensitive than qRTPCR assay in diagnosing invasive pulmonary aspergillosis in rats.
\end{abstract}

Keywords: Invasive Pulmonary Aspergillosis; Aspergillus; Galactomannan Antigen; Quantitative Real-Time PCR; Receiver Operating Characteristic Curve; Rat Model

\section{Introduction}

The prevalence of invasive fungal infections and consequent mortality has increased throughout the last 2 decades, and the reported mortality from an epidemiological study covering the period from 2002 to 2006 is $28.6 \%$ [1]. According to the TRANSNET database, half of extensive fungal infections are caused by Aspergillus sp. [2]. Most fungal infections occur in immunodeficient individuals, such as transplant recipients or those with leukemia receiving chemotherapy, and pathological exacerbations of lung infections and the inability to diagnose fungal infections are the major causes of death in these patients $[3,4]$. Early diagnosis of invasive fungal infections is critical for rapid treatment [3], but the lack of sensitive and spe-

*Yanli Xin and Jiancong Lin equally contributed to this manuscript. The authors declare that they have no competing interests.

${ }^{\#}$ Corresponding author. cific clinical symptoms and radiological patterns for invasive aspergillosis (IA) hinders early diagnosis. Traditional histopathological examination and fungal culture relying on invasive procedures are relatively insensitive and not commonly used in clinical diagnosis due to the challenges of sampling pulmonary fluids or tissues from critically ill patients. While examination of bronchialveolar lavage (BAL) fluid yields a higher detection rate than examination of blood or serum [5-7], obtaining BAL fluid is invasive, and many patients with IA have other severe diseases which limit BAL collection. Consensus on the most reliable assays to detect IA from minimally or noninvasive samples has not been reached, and is a major topic of current research $[8,9]$.

Galactomannan (GM) is a cell wall component of Aspergillus, and its production increases during Aspergillus growth. Assays that detect fungal antigens such as GM 
by enzyme-linked immunosorbent assay (GM assay) or Aspergillus DNA by polymerase chain reaction (PCR) are emerging diagnostic methods; however, their specificity and sensitivity require additional characterization and refinement. The sensitivity of the GM assay ranges from $60 \%$ to $100 \%$ for infected Aspergillus samples, and the specificity ranges from $80 \%$ to $100 \%$ [10-14]. The cut-off value has a significant impact on diagnosis because of cross-reactivity $[8,12,15-17]$. Furthermore, treatment with anti-fungal therapies decreases the fungal load and reduces the GM concentration, which can fall below the detectable limit of the GM assay [18]. Given the advantage of high sensitivity, a PCR assay coupled with an ELISA assay (PCR-ELISA) has been used for detection of Aspergillus [19,20]. However, poor specificity has been noted due to several interference factors, including environmental contamination [19]. In addition, the PCRELISA assay is more cumbersome for clinical laboratories [5].

Recently, a quantitative real-time PCR (qRT-PCR) assay was developed that may overcome the shortcomings of other methods [8,21]. qRT-PCR analysis of serum samples of patients with hematological malignancies at risk for IA was shown to have a sensitivity of $72.7 \%$ [5]. A commercially available qRT-PCR for the detection of Aspergillus DNA (MycAssay ${ }^{\mathrm{TM}}$ Aspergillus) has shown a sensitivity of $60 \%-70 \%$ and a specificity of $95 \%$ for the detection of IA [22]. However, a study by Scotter $e t$ al. [19] indicated that GM testing by ELISA and the PCR-ELISA were more capable of early detection of fungal infection than RT-PCR examination.

The aim of the study is to compare the sensitivity and specificity of the GM assay to the Aspergillus-specific nucleic acid qRT-PCR assay in a rat model of pulmonary IA.

\section{Methods}

\subsection{Aspergillus fumigatus Preparation}

Lyophilized Aspergillus fumigatus (A. fumigatus) was recovered in $0.5 \mathrm{~mL}$ sterile broth, cultured in Sabouraud agar medium at $37^{\circ} \mathrm{C}$ for $48 \mathrm{~h}$, and subsequently at $30^{\circ} \mathrm{C}$ for 3 - 5 days. Spores were eluted from the agar surface with $10 \mathrm{~mL}$ PBS containing $0.05 \%$ Tween- 80 . The suspension was filtered through 8 layers of sterile gauze to remove hyphae. The spore suspension was then transferred to a $15-\mathrm{mL}$ tube and centrifuged at $10,000 \times \mathrm{g}$ for $15 \mathrm{~min}$. The supernatant was discarded, and the pellet containing spores was resuspended in normal saline. Spore count was determined on a blood count plate, and the concentration was adjusted to $8 \times 10^{5}$ spores/L. Spore viability was determined by culture of serial dilutions of the spore suspension.

\subsection{Induction of Pulmonary Aspergillosis in Rats}

Neutropenic rats were infected with Aspergillus as described by Zhang et al. [23]. Briefly, male SpragueDawley rats (specific pathogen free; 8 weeks old; weight, $200 \pm 20 \mathrm{~g}$ ) were housed with food and water ad libatum according to animal care guidelines. Rats received one of four treatments: immunosuppression and A. fumigatus infection $(n=48)$, immunosuppression (no infection, $n=$ 6 ), infection (no immunosuppression, $n=6$ ) and vehicle control (no immunosuppression, no infection, $n=12$ ). Persistent immunosuppression was induced in the indicated groups by intraperitoneal injection of cyclophosphamide, as described by Leenders et al. [24]. The dosage of cyclophosphamide was determined by a preliminary experiment. Cyclophosphamide $(50 \mathrm{mg} / \mathrm{kg}$ i.p.) was injected 5 days prior to the Aspergillus spore suspension inoculation. A second cyclophosphamide injection (40 $\mathrm{mg} / \mathrm{kg}$ ) was performed 1 day prior to inoculation, and a third injection $(30 \mathrm{mg} / \mathrm{kg})$ was performed on day 3 after inoculation. Control groups were injected with an equivalent volume of normal saline. After treatment with cyclophosphamide, all rats were consistently kept in a clean environment, and injected with levofloxacin, 10 $\mathrm{mg} / \mathrm{kg} / \mathrm{d}$.

Immunosuppressed and normal rats of the indicated groups were infected with $A$. fumigatus $\left(8 \times 10^{5}\right.$ spores $)$ after anesthesia (chloral hydrate (3.5 mL/kg i.p.) and intubation. After connecting the endotracheal tube with a syringe, $0.1 \mathrm{~mL}$ of the spore suspension was injected. Rats were kept erect and rotated for 30 seconds, ensuring that the inoculation entered the trachea and was distributed evenly in both lungs. Rats were sacrificed after $1-7$ days and whole blood was collected by heart puncture.

Rats which received both immunosuppression and infection $(n=48)$ were sacrificed on days $1,3,5$, and 7 after inoculation, and were referred to as group 1, 2, 3, and 4 , respectively ( $n=12$ /group). Four $\mathrm{ml}$ of whole blood was collected and $3 \mathrm{~mL}$ blood was used to determine Aspergillus DNA using the qRT-PCR method, and $100 \mu \mathrm{L}$ of serum was prepared to measure the GM concentrations using the ELISA method. Lung tissue was collected for biopsy and tissue culture.

\subsection{Isolation of $A$. fumigatus DNA from Blood}

A.fumigatus DNA was isolated as described previously [25]. We used the physical method of grinding, similar to the bead beating, to break the cell walls of the fungi to release fungal DNA. The efficiency of fungal DNA extraction was about $96.8 \%$. In brief, $3 \mathrm{~mL}$ of whole blood were treated with $1 \mathrm{~mL}$ of EDTA anticoagulant, lysed in $1 \mathrm{~mL}$ of erythrocyte lysis buffer $(0.01 \mathrm{~mol} / \mathrm{L}$ Tris- $\mathrm{HCl} \mathrm{pH}$ 
7.6, $0.01 \mathrm{~mol} / \mathrm{L} \mathrm{NaCl}, 0.005 \mathrm{~mol} / \mathrm{L} \mathrm{MgCl}_{2}$ ), mixed thoroughly, and further treated with $1 \mathrm{~mL}$ of lysis buffer twice, allowing extensive erythrocyte lysis. After centrifuged at $8000 \times \mathrm{g}$ for $10 \mathrm{~min}$, the pellet was washed with normal saline, treated with $100 \mu \mathrm{L}$ proteinase $\mathrm{K}$ lysis buffer (20 mM Tris-HC1, $2.0 \mathrm{mM}$ EDTA, 1.0\% Triton $\mathrm{X}-100,2 \mathrm{mg} / \mathrm{mL}$ proteinase $\mathrm{K}$ ), and subsequently $50 \mu \mathrm{L}$ lysostaphin at a concentration of $50 \mu \mathrm{g} / \mathrm{mL}$. The lysate was incubated at $60^{\circ} \mathrm{C}$ for $60 \mathrm{~min}$, treated with an equivalent volume of phenol, chloroform, and isoamyl alcohol. Thirty $\mu \mathrm{L}$ of $A$ fumigatus DNA was precipitated using ethanol, centrifuged at $12000 \mathrm{rpm} / \mathrm{min}$ for $20 \mathrm{~min}$, and dissolved in Tris-EDTA buffer $(10 \mathrm{mM}$ Tris-Cl, $\mathrm{pH}$ 7.5 with $1 \mathrm{mM}$ EDTA) for reserve.

\subsection{Polymerase Chain Reaction and Product Analysis}

Specific primers were based on the target mRNA sequence in GeneBank, harboring the CDS region of the mitochondrial translation optimization gene Mto1 of A. fumigatus. Primers were designed using Primer Express 2.0 software: forward primer, 5'-tttctccacccaggaacgtt-3'; reverse primer, 5'-cgaatccggagaggtgatacc-3'; probe, 5'FAM-cagttgtgatgacgacacgcccagt-TAMRA-3'. Primers were synthesized using the ABI 3900 high-throughput DNA synthesizer. To determine the specificity of the qRT-PCR reaction, the aforementioned primers were assessed for their ability to amplify DNA from A. niger, A. flavus, A. terreus, Candida albicans, Cryptococcus neoformans, Staphylococcus aureus, and Pseudomonas aeruginosa [26].

The qRT-PCR reaction $(50 \mu \mathrm{L})$ included $10 \mu \mathrm{L}$ of $5 \times$ reaction buffer $(10 \mathrm{mM}$ Tris- $\mathrm{HCl} \mathrm{pH} 8.0,50 \mathrm{mM} \mathrm{KCl}, 2$ $\mathrm{mM} \mathrm{MgCl} 2), 10 \mathrm{pmol}$ of each primer $(10 \mathrm{pmol} / \mathrm{uL}), 2 \mu \mathrm{L}$ dNTPs $(10 \mathrm{mM}), 3 \mathrm{U}$ Taq DNA polymerase, and $4 \mu \mathrm{L}$ cDNA or positive standard. Reaction was performed as follows: $93^{\circ} \mathrm{C}$ for $3 \mathrm{~min}$, and 40 cycles of $93^{\circ} \mathrm{C} 30 \mathrm{~s}$, $55^{\circ} \mathrm{C} 45 \mathrm{~s}$. Real-time PCR was carried out in an automated fluorescent quantitative PCR cycler (ABI 7500), and the amplification curve was analyzed based on the exponential amplification and $\mathrm{Ct}$ value (cycle threshold). The $\mathrm{Ct}$ was defined as the number of cycles required for the fluorescent signal to cross the threshold (i.e., exceed background level). The $\mathrm{Ct}$ value was dose-dependent on the positive standard

The standard curve quantification method used the target gene synthesized in Sangon (Shanghai). Ten-fold serial dilutions of the positive standard were prepared to produce the quantitative qRT-PCR gradients. Distilled water was used as a negative control. The optical density (OD) $260 / 280$ of the purified DNA was $>1.8$, and thus qualified. DNA concentration (copies $/ \mu \mathrm{L}$ ) was calculated with OD 260 over the fragment length, namely the posi- tive standard. After dilution of recombinant plasmid, qRT-PCR amplification was performed following the optimal procedures. The LOD was measured according to amplification curve derived from qRT-PCR. The correlation between $\mathrm{Ct}$ value and DNA copy was $\mathrm{Ct}=$ $-3.347424 \times \log$ copy number +35.885406 .

\subsection{GM Antigen Detection (GM Assay)}

The GM assay was performed using the Platelia Aspergillus kit (Bio-Rad Corporation, France), following the manufacturer's instructions for the preparation of samples. Optical densities (OD) at a primary wavelength of $450 \mathrm{~nm}$ and a secondary wavelength of $620 \mathrm{~nm}$ were determined. In each experiment, positive serum control, negative serum control, standardized control, and serum samples were run in triplicate. The mean OD derived from the standardized control was used as a standard (GM OD Index = OD of sample/OD of standard serum), and kept in the range of 0.3 to 0.8 . All experiments were internally controlled: The ratio of OD from the positive control to OD from the standard was over 2, and the ratio of OD from the negative control to the OD of the standard was below 0.4 .

\subsection{Histopathological Examination and Tissue Culture}

Rats that received both cyclophosphamide and infection were sacrificed on 1, 3, 5, and 7 days after $A$. fumigatus inoculation ( $n=12$ each group). Rats in the other groups were sacrificed on day 7. Blood samples and right lung tissue were used for fungal culture described above. The left lung tissue was fixed in $10 \%$ formalin and embedded in paraffin. The paraffin sections were primarily stained with hematoxylin \& eosin (HE), and further with periodic acid-Schiff stain followed by histopathological examination.

\subsection{Statistical Analysis}

The values of the GM concentration for each group were reported as mean \pm standard deviation. Wilcoxon rank sum test was used to analyze the difference between each two groups. A receiver operating characteristic (ROC) curve was created with the statistical software used for all analyses (SPSS version 16.0). A value of $p<0.05$ was considered to indicate statistical significance.

\section{Results}

\subsection{Histopathology of Pulmonary A. fumigatus Infection}

Immunosuppressed, infected rats showed progressive accumulation of hyphae in the alveoli (Figure 1). Many 


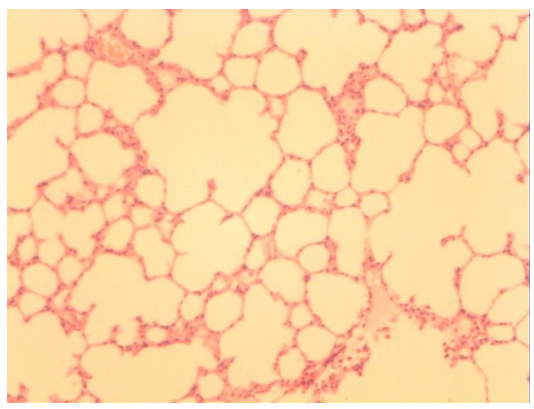

(a)

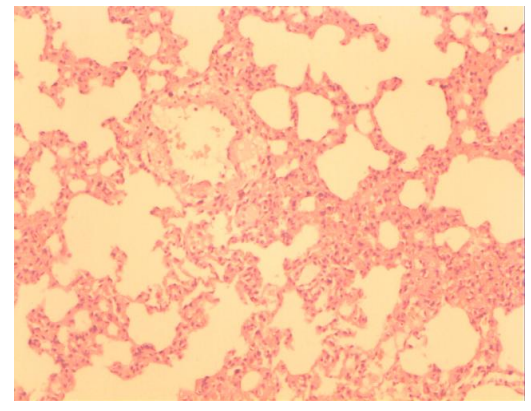

(b)

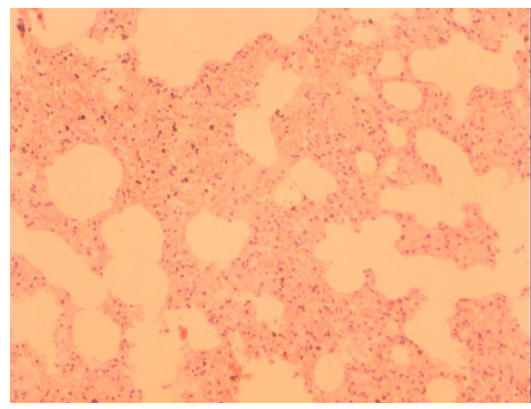

(c)

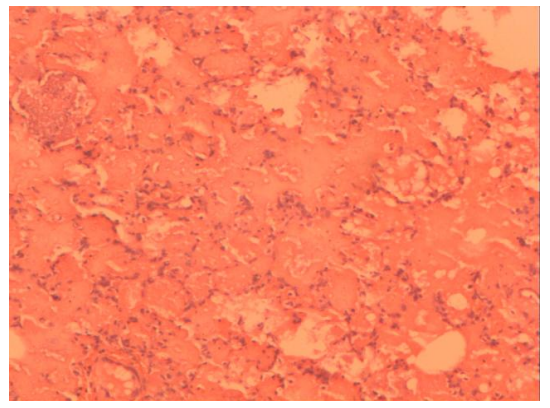

(d)

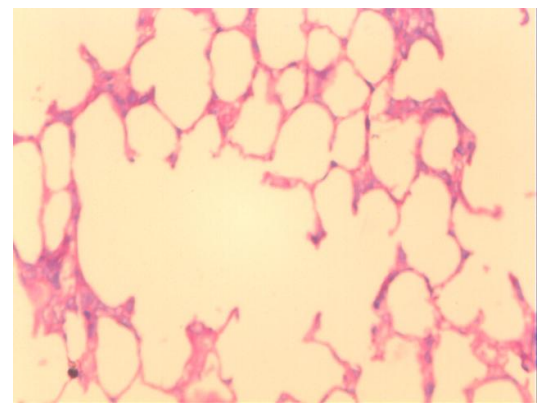

(e)

Figure 1. Histopathological analysis. Lung tissues were harvested from immunosuppressed, infected rats on day 1(a), 3(b),

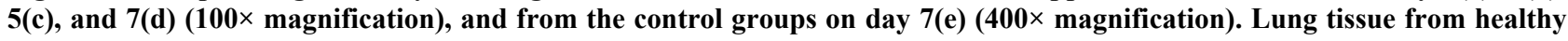
controls.

Aspergillus spores and mild inflammation were found in the lung tissue of the neutropenic rats on the 1st day post infection (Figure 1(a)). On the $3^{\text {rd }}$ day, the alveoli exhibited accumulated spores, a small presence of hyphae, hyperplasia of alveolar epithelial cells, and broadened alveolar septa. Cellulose exudate and hemorrhage in the alveolar spaces were also observed (Figure 1(b)). On the $5^{\text {th }}$ day post-infection abnormal morphology of the alveolar structures was apparent, and the spores had bloomed: hollow, colorless and acute angle-branching hyphae and granuloma were present (Figure 1(c)). Clear exudate was located in the alveolar spaces, and severe hemorrhage was evident in the capillaries. The alveolar septa had broadened, and part of the alveolar structure was damaged. On the $7^{\text {th }}$ day, the aforementioned characteristics had become more apparent and the alveolar structure was no longer clear (Figure 1(d)). The alveoli of the vehicle control group had normal morphology (Figure 1(e)) No apparent inflammation was noted in nonimmunosuppressed infected mice.

\subsection{Detection of $A$. fumigatus DNA Isolated from Immunosuppressed-Infected Rats}

No A. fumigatus target sequence was amplified from the uninfected control group (immunosuppression and no infection, $n=6$ ), and vehicle control group (no immunosuppression, no infection, $n=12$ ). The target sequence was successfully amplified in 14 out of 48 samples from immunosuppressed-infected rats. The 14 positive samples were obtained on day 5 (6/12), and day 7 (8/12): no positive samples were obtained on day 1 or day 3 . No DNA was identified in the no immunosuppression/infection control samples $(0 / 6)$ or in the no infection/immunosuppression control samples (0/6).

Amplification curve and quantitative analysis showed that the DNA content ranged from $5 \times 10^{2}$ to $5.77 \times 10^{3}$ copies $/ \mu \mathrm{L}$ of blood. The lower limit for qRT-PCR detection was 100 copies $/ \mu \mathrm{L}$ of blood, and was determined according to amplification curve derived from qRT-PCR. Only samples from infected animals yielded positive RT-PCR curves, and the PCR reactions spiked with DNA from A. niger, A. flavus, A. terreus, Candida albicans, Cryptococcus neoformans, Staphylococcus aureus, and Pseudomonas aeruginosa yielded negative results. Thus, the primer set for A. fumigatus showed high specificity. Receiver operating characteristic curve (ROC) analysis indicated a Ct cut-off value of 15.35 , and the area under the curve (AUC) was 0.627 .

\subsection{Determination of GM by ELISA}

A commercial kit was utilized for the determination of GM, and the mean concentrations for each group are shown in Table 1. As expected, the concentration of GM increased from day 1 to day 7 , in agreement with the 
Table 1. qPCR detction of Mto1 gene copy number and serum GM levels.

\begin{tabular}{cccc}
\hline \multicolumn{1}{c}{ Group } & Number Positive/Total & Serum GM level (index) & qPCR of blood (copies/ $\mathbf{\mu L})$ \\
\hline Infection and immunosuppression & & & \\
Day 1 (group 1) & $5 / 12$ & $1.236 \pm 0.169$ & NA \\
Day 3 (group 2) & $9 / 12$ & $1.889 \pm 0.247$ & NA \\
Day 5 (group 3) & $12 / 12$ & $2.548 \pm 0.218$ & $35.29 \pm 31.25$ \\
Day 7 (group 4) & $12 / 12$ & $3.520 \pm 0.215$ & $1183.69 \pm 1653.60$ \\
Control groups at Day 7 & & & NA \\
Immunosuppression/no infection & $0 / 6$ & $0.857 \pm 0.103$ & NA \\
No immunosuppression/infection & $0 / 6$ & $0.683 \pm 0.130$ & NA \\
No immunosuppression/no infection & $0 / 12$ & $0.600 \pm 0.109$ & \\
\hline
\end{tabular}

$\mathrm{NA}=$ could not be detected. Wilcoxon rank sum test showed that the serum GM levels in the immunosuppressed infected animals at day $1,3,5$, and 7 were significantly different from the control groups $(\mathrm{p}<0.01$ ). A significant difference was also present between group 1 and group 4 ( $\mathrm{p}<0.01$ ). No significant difference was observed in the GM levels between the three control groups (all, $\mathrm{p}>0.05$ ).

infiltration observed in the histopathological specimens. The GM assay detected antigen in only some of the infected animals (group 1, 5/12; group 2, 9/12; group 3, $12 / 12$; group 4, 12/12; infection control, 0/6). Since only samples from infected animals tested positive in the GM assay, the specificity for the GM assay was $100 \%$, and the sensitivity was $79.2 \%$. The ROC of the GM assay indicated that the optimal cut-off value was 1.40 (specificity, 100\%; AUC, 0.919).

\section{Discussion}

In this study, the efficacies of GM assay and qRT-PCR assays for the detection of Aspergillus infection were evaluated in a well-established rat model of pulmonary IA. The results showed that while both assays were $100 \%$ specific for the diagnosis of IA and GM assay exhibited much greater sensitivity and allowed for earlier detection.

Serum-based assays for diagnosis of Aspergillus infection have been sought for at least four decades, but inadequate sensitivity has restricted the general application of many methods [8]. A commercial ELISA method measures GM antigen at concentrations as low as $0.5-1$ $\mathrm{ng} / \mathrm{mL}$, depending on the cutoff value $[23,25]$. Our cutoff value of 1.4 provided a sensitivity of $79.2 \%$ for days 1 - 7 infected samples in this immunosuppressed rat model. Using an A. fumigatus-infected guinea pig model, McCulloch et al. [18] found that the GM assay was able to detect $A$. fumigatus infection in samples from $0 / 3$ animals on day $1,1 / 3$ on day 2 , and $3 / 3$ on days $3-5$ for an overall sensitivity of $67 \%$. Lengerova et al. [6] observed a $100 \%$ sensitivity in BAL fluids in an IA rat model, but only a $26 \%$ sensitivity in serum samples (1/5 on day 3 ,
0/5 day 5, 3/5 day 7). Becker et al. [13] found that GM assay detected GM in $8 \%$ of day 1 samples in an IA rat model, $89 \%$ of day 3 samples, and reached $100 \%$ by day 7. In comparison, our results showed that GM was detected in the sera of 5 of 12 samples on day 1,9 of 12 samples on day 3, and all samples on day 5 and day 7 , which were consistent with those of reports [18]. The commercially available MycAssay Aspergillus DNA assay and an "in house" qRT-PCR assay have shown promise in the clinical diagnosis of IA via testing BAL fluid samples [27]. Compared with conventional PCR, qRT-PCR lowers the risk of cross-contamination by using a sealed tube during amplification and detection. The fluorescence signal generation depends on both probe-template recognition and amplification of template, ensuring the high specificity of qRT-PCR method. Although Aspergillus sp. DNA was usually detected at a higher frequency in BAL samples [27], Hadrich et al. [5] observed that RT-PCR and PCR-ELISA assays exhibited higher sensitivities in serum samples than in BAL samples, with sensitivities ranging from $64 \%-94 \%$. In our rat model, the sensitivity of the qRT-PCR was $25 \%$ with whole blood samples harvested from infected, immunosuppressed rats on days $1-7$, which was similar to the $26 \%$ sensitivity using serum samples from a guinea pig IA model (days 1 - 7) reported by Lengerova et al. [6]. Likewise, Becker et al. [13] found that in an IA rat model PCR did not detect Aspergillus DNA from day 1 or 2 serum samples, but the sensitivity improved from $20 \%$ on day 3 to $40 \%$ on day 7 , and the authors concluded that the sensitivity may be related to the methodology. One obvious difference between humans and animal models is that in most cases humans will have sought testing due to the presence of symptoms, suggesting a more fulminant Aspergillus in- 
fection at time of sampling than the early time points in animal models. Presumably, the longer incubation period would favor Aspergillus replication, and may promote alveolar damage and seepage of more Aspergillus spores into the blood.

In this study, analysis of qRT-PCR results showed that an AUC of 0.627 produced the maximum specificity, and although highly consistent with the pathological changes in lung tissue the qRT-PCR method was not sufficiently sensitive $(25.9 \%)$ to solely rely on for early diagnosis. In contrast, the AUC of the GM assay was significantly higher (0.919), and was able to detect Aspergillus in 79\% of day 1 - 7 samples. Interestingly, Torelli et al. [27] described a cohort of patients with suspected IA, and $>90 \%$ of patients with BAL samples that were positive for Aspergillus DNA by MycAssay and RT-PCR also had GM-positive BAL samples. Together, it seems that GM assay and qRT-PCR assays both are capable of early detection of Aspergillus infection but further study for establishing a gold standard is warranted [28].

\section{Acknowledgements}

The research was supported by Science and Technology Planning Project of Guangdong Province, China, No. 2011B090400118, No. 2009B03081137 and Guangzhou Public Health Bureau (Grant No. 2009-YB-181, 2009YB-183).

\section{REFERENCES}

[1] C. Hahn-Ast, A. Glasmacher, S. Muckter, A. Schmitz, A. Kraemer, G. Marklein, P. Brossart and M. von LilienfeldToal, "Overall Survival and Fungal Infection-Related Mortality in Patients with Invasive Fungal Infection and Neutropenia after Myelosuppressive Chemotherapy in a Tertiary Care Centre from 1995 to 2006," Journal of Antimicrobial Chemotherapy, Vol. 65, No. 4, 2010, pp. 761768. http://dx.doi.org/10.1093/jac/dkp507

[2] A. H. Groll and L. McNeil Grist, "Current Challenges in the Diagnosis and Management of Invasive Fungal Infections: Report from the 15th International Symposium on Infections in the Immunocompromised Host: Thessaloniki, Greece, 22-25 June 2008," International Journal of Antimicrobial Agents, Vol. 33, No. 2, 2009, pp. 101-104. http://dx.doi.org/10.1016/j.ijantimicag.2008.08.014

[3] M. von Eiff, N. Roos, R. Schulten, M. Hesse, M. Zuhlsdorf and J. van de Loo, "Pulmonary aspergillosis: Early Diagnosis Improves Survival," Respiration, Vol. 62, No. 6, 1995, pp. 341-347. http://dx.doi.org/10.1159/000196477

[4] G. Chamilos, M. Luna, R. E. Lewis, G. P. Bodey, R. Chemaly, J. J. Tarrand, A. Safdar, I. I. Raad and D. P. Kontoyiannis, "Invasive Fungal Infections in Patients with Hematologic Malignancies in a Tertiary Care Cancer Center: An Autopsy Study over a 15-Year Period (19892003)," Haematologica, Vol. 91, No. 7, 2006, pp. 986-989.
[5] I. Hadrich, C. Mary, F. Makni, M. Elloumi, H. Dumon, A. Ayadi and S. Ranque, "Comparison of PCR-ELISA and Real-Time PCR for Invasive Aspergillosis Diagnosis in Patients with Hematological Malignancies," Medical Mycology, Vol. 49, No. 5, 2011, pp. 489-494.

[6] M. Lengerova, I. Kocmanova, Z. Racil, K. Hrncirova, S. Pospisilova, J. Mayer, L. K. Najvar, N. P. Wiederhold, W. R. Kirkpatrick ad T. F. Patterson, "Detection and Measurement of Fungal Burden in a Guinea Pig Model of Invasive Pulmonary Aspergillosis by Novel Quantitative Nested Real-Time PCR Compared with Galactomannan and (1,3)-Beta-D-glucan Detection," Journal of Clinical Microbiology, Vol. 50, No. 3, 2012, pp. 602-608. http://dx.doi.org/10.1128/JCM.05356-11

[7] V. R. Aquino, F. Nagel, H. F. Andreolla, F. de-Paris, M. O. Xavier, L. Z. Goldani, D. W. Denning and A. C. Pasqualotto, "The Performance of Real-Time PCR, Galactomannan, and Fungal Culture in the Diagnosis of Invasive Aspergillosis in Ventilated Patients with Chronic Obstructive Pulmonary Disease (COPD)," Mycopathologia, Vol. 174, No. 2, 2012, pp. 163-169. http://dx.doi.org/10.1007/s11046-012-9531-1

[8] M. J. Ruping, J. J. Vehreschild, A. Groll, C. Lass-Florl, H. Ostermann, M. Ruhnke and O. A. Cornely, "Current Issues in the Clinical Management of Invasive Aspergillosis-The AGIHO, DMykG, OGMM and PEG Web-Based Survey and Expert Consensus Conference 2009," Мусоses, Vol. 54, No. 5, 2011, pp. e557-e568. http://dx.doi.org/10.1111/j.1439-0507.2010.01989.x

[9] Y. Zhao, S. Park, P. Warn, R. Shrief, E. Harrison and D. S. Perlin, "Detection of Aspergillus fumigatus in a Rat Model of Invasive Pulmonary Aspergillosis by Real-Time Nucleic Acid Sequence-Based Amplification," Journal of Clinical Microbiology, Vol. 48, No. 4, 2010, pp. 13781383. http://dx.doi.org/10.1128/JCM.02214-09

[10] M. Hoenigl, H. J. Salzer, R. B. Raggam, T. Valentin, A. Rohn, A. Woelfler, et al., "Impact of Galactomannan Testing on the Prevalence of Invasive Aspergillosis in Patients with Hematological Malignancies," Medical Mycology, Vol. 50, No. 3, 2012, pp. 266-269. http://dx.doi.org/10.3109/13693786.2011.603102

[11] I. Hadrich, F. Makni, F. Cheikhrouhou, S. Neji, I. Amouri, H. Sellami, H. Trabelsi, H. Bellaaj, M. Elloumi and A. Ayadi, "Clinical Utility and Prognostic Value of Galactomannan in Neutropenic Patients with Invasive Aspergillosis," Pathologie Biologie (Paris), Vol. 60, No. 6, 2012, pp. 357-361.

http://dx.doi.org/10.1016/j.patbio.2011.10.011

[12] T. J. Walsh, M. C. Wissel, K. J. Grantham, R. Petraitiene, V. Petraitis, M. Kasai, A. Francesconi, M. P. Cotton, J. E. Hughes, L. Greene, et al., "Molecular Detection and Species-Specific Identification of Medically Important Aspergillus Species by Real-Time PCR in Experimental Invasive Pulmonary Aspergillosis," Journal of Clinical Microbiology, Vol. 49, No. 12, 2011, pp. 4150-4157. http://dx.doi.org/10.1128/JCM.00570-11

[13] M. J. Becker, S. de Marie, D. Willemse, H. A. Verbrugh and I. A. Bakker-Woudenberg, "Quantitative Galactomannan Detection Is Superior to PCR in Diagnosing and 
Monitoring Invasive Pulmonary Aspergillosis in an Experimental Rat Model," Journal of Clinical Microbiology, Vol. 38, No. 4, 2000, pp. 1434-1438.

[14] M. M. Leeflang, Y. J. Debets-Ossenkopp, C. E. Visser, R. J. Scholten, L. Hooft, H. A. Bijlmer, J. B. Reitsma, P. M. Bossuyt and C. M. Vandenbroucke-Grauls, "Galactomannan Detection for Invasive Aspergillosis in Immunocompromized Patients," Cochrane Database of Systematic Reviews, Vol. 8, No. 4, 2008, Article ID: 007394.

[15] S. F. Yeo and B. Wong, "Current Status of Nonculture Methods for Diagnosis of Invasive Fungal Infection," Clinical Microbiology Review, Vol. 15, No. 3, 2002, pp. 465-484. http://dx.doi.org/10.1128/CMR.15.3.465-484.2002

[16] L. Millon, F. Grenouillet, J. Crouzet, F. Larosa, S. Loewert, A. P. Bellanger, E. Deconinck and F. Legrand, "FalsePositive Aspergillus Real-Time PCR Assay Due to a Nutritional Supplement in a Bone Marrow Transplant Recipient with GVH Disease," Medical Mycology, Vol. 48, No. 4, 2010, pp. 661-664. http://dx.doi.org/10.3109/13693780903451836

[17] T. J. Walsh, S. Shoham, R. Petraitiene, T. Sein, R. Schaufele, A. Kelaher, H. Murray, C. Mya-San, J. Bacher and V. Petraitis, "Detection of Galactomannan Antigenemia in Patients Receiving Piperacillin-Tazobactam and Correlations between in Vitro, in Vivo, and Clinical Properties of the Drug-Antigen Interaction," Journal of Clinical Microbiology, Vol. 42, No. 10, 2004, pp. 4744-4748. http://dx.doi.org/10.1128/JCM.42.10.4744-4748.2004

[18] E. McCulloch, G. Ramage, R. Rajendran, D. F. Lappin, B. Jones, P. Warn, R. Shrief, W. R. Kirkpatrick, T. F. Patterson and C. Williams, "Antifungal Treatment Affects the Laboratory Diagnosis of Invasive Aspergillosis," Journal of Clinical Pathology, Vol. 65, No. 1, 2012, pp. 83-86. http://dx.doi.org/10.1136/jcp.2011.090464

[19] J. M. Scotter and S. T. Chambers, "Comparison of Galactomannan Detection, PCR-Enzyme-Linked Immunosorbent Assay, and Real-Time PCR for Diagnosis of Invasive Aspergillosis in a Neutropenic Rat Model and Effect of Caspofungin Acetate," Clinical and Diagnostic Laboratory Immunology, Vol. 12, No. 11, 2005, pp. 13221327.

[20] F. Suarez, O. Lortholary, S. Buland, M. T. Rubio, D. Ghez, V. Mahe, G. Quesne, S. Poiree, A. Buzyn, B. Varet, et al., "Detection of Circulating Aspergillus fumigatus DNA by Real-Time PCR Assay of Large Serum Volumes Improves Early Diagnosis of Invasive Aspergillosis in HighRisk Adult Patients under Hematologic Surveillance," Journal of Clinical Microbiology, Vol. 46, No. 11, 2008, pp. 3772-3777. http://dx.doi.org/10.1128/JCM.01086-08

[21] M. L. Luong, C. J. Clancy, A. Vadnerkar, E. J. Kwak, F.
P. Silveira, M. C. Wissel, K. J. Grantham, R. K. Shields, M. Crespo, J. Pilewski, et al., "Comparison of an Aspergillus Real-Time Polymerase Chain Reaction Assay with Galactomannan Testing of Bronchoalvelolar Lavage Fluid for the Diagnosis of Invasive Pulmonary Aspergillosis in Lung Transplant Recipients," Clinical Infectious Diseases, Vol. 52, No. 10, 2011, pp. 1218-1226. http://dx.doi.org/10.1093/cid/cir185

[22] P. L. White, M. D. Perry, A. Moody, S. A. Follett, G. Morgan and R. A. Barnes, "Evaluation of Analytical and Preliminary Clinical Performance of Myconostica MycAssay Aspergillus When Testing Serum Specimens for Diagnosis of Invasive Aspergillosis," Journal of Clinical Microbiology, Vol. 49, No. 6, 2011, pp. 2169-2174. http://dx.doi.org/10.1128/JCM.00101-11

[23] C. R. Zhang, Y. C. Tang, K. Kawakami, T. T. Zhang, K. X. Zhang and J. X. Zhu, "An Experimental Study of the Therapeutic Effect of Interleukin-2 and Interleukin-12 with and without Amphotericin B on Pulmonary Fungal Infection," Zhonghua Jie He He Hu Xi Za Zhi, Vol. 27, No. 4, 2004, pp. 234-236.

[24] A. C. Leenders, S. de Marie, M. T. ten Kate, I. A. BakkerWoudenberg and H. A. Verbrugh, "Liposomal Amphotericin B (AmBisome) Reduces Dissemination of Infection as Compared with Amphotericin B Deoxycholate (Fungizone) in a Rate Model of Pulmonary Aspergillosis," Journal of Antimicrobial Chemotherapy, Vol. 38, No. 2, 1996, pp. 215-225. http://dx.doi.org/10.1093/jac/38.2.215

[25] J. Loffler, H. Hebart, U. Schumacher, H. Reitze and H. Einsele, "Comparison of Different Methods for Extraction of DNA of Fungal Pathogens from Cultures and Blood," Journal of Clinical Microbiology, Vol. 35, No. 12, 1997, pp. 3311-3312.

[26] J. Liu, Y. Shi, D. He, P. Liu, Y. Zhang, L. Xu and L. Wang, "Development of Real-Time PCR Method to Detect Aspergillus fumigates," Biotechnology, Vol. 19, No. 1, 2009, pp. 34-36.

[27] R. Torelli, M. Sanguinetti, A. Moody, L. Pagano, M. Caira, E. De Carolis, L. Fuso, G. De Pascale, G. Bello, M. Antonelli, et al., "Diagnosis of Invasive Aspergillosis by a Commercial Real-Time PCR Assay for Aspergillus DNA in Bronchoalveolar Lavage Fluid Samples from High-Risk Patients Compared to a Galactomannan Enzyme Immunoassay," Journal of Clinical Microbiology, Vol. 49, No. 12, 2011, pp. 4273-4278. http://dx.doi.org/10.1128/JCM.05026-11

[28] M. A. Mennink-Kersten, J. P. Donnelly and P. E. Verweij, "Detection of Circulating Galactomannan for the Diagnosis and Management of Invasive Aspergillosis," Lancet Infectious Disease, Vol. 4, No. 6, 2004, pp. 349-357. http://dx.doi.org/10.1016/S1473-3099(04)01045-X 